\title{
9. LA REFORMA CONSTITUCIONAL EN EL DERECHO DE SINDICACIÓN Y DE HUELGA
}

\author{
M. ${ }^{a}$ LUISA BALAGUER CALLEJÓN \\ Profesora Titular de Derecho Constitucional \\ Universidad de Málaga
}




\section{SUMARIO}

INTRODUCCIÓN.-I. LA FASE CONSTITUYENTE.-II. EL DESARROLLO LEGISLATIVO Y LA JURISPRUdenCia del TRIBUNAL CONSTITUCIONAL.-III. CONCLUSIONES DE LA PONENCIA RESPECTO A LA IDEA CENTRAL DE REFORMA DE LACE. 


\title{
9. LA REFORMA CONSTITUCIONAL EN EL DERECHO DE SINDICACIÓN Y DE HUELGA
}

\author{
POR \\ M. ${ }^{a}$ LUISA BALAGUER CALLEJÓN \\ Profesora Titular de Derecho Constitucional \\ Universidad de Málaga \\ INTRODUCCIÓN
}

La reforma de la Constitución es todavía una posibilidad remota y poco pensable a corto plazo, habida cuenta la virtualidad de la Constitución Española, de gran flexibilidad y adaptabilidad.

Pero esta circunstancia, enraizada más en la coyuntura política y en la realidad social que en la posibilidad jurídica, no empece el estudio de las posiciones doctrinales que quepa formular con respecto a la situación de constitutione ferenda, en la medida en que éstas son significadamente estudiadas desde este particular ángulo de visión que pretende situar la reforma en el marco de la experiencia jurídica de la interpretación judicial en el ámbito del Tribunal Constitucional y de la jurisdicción ordinaria.

$Y$ desde este específico punto de vista, hay que tener en cuenta que determinados artículos de la Constitución, en relación con el desarrollo social y político subyacente, son más susceptibles de reforma que otros. En concreto, aquellas instituciones que han tenido una mayor incidencia en el desarrollo de la democracia, con un compromiso social implícito, y algunas otras que han demostrado un cierto grado de anacronismo, pero que no pueden suprimirse sin más, porque ligeramente retocadas pueden ser de una utilidad alternativa no menos importante (Senado), o en su caso, otros que por evolución de conceptos como el de soberanía, que amplían su contenido (elecciones y sufragio pasivo), conllevan una necesaria modificación. 
En lo que se refiere a la cuestión concreta del sindicalismo, libertad de sindicación y huelga, la situación ha evolucionado desde una mera tolerancia de los poderes públicos, hasta una tutela judicial al ejercicio del derecho. La evolución de la realidad social nos permite fijar una posición respecto de una eventual reforma y su necesidad. Y la posición a formular ha de ser cauta y restringida. La cautela proviene de la necesidad de que las formulaciones respecto de los cambios en el ordenamiento vayan encaminadas a la desaparición de los problemas que una norma plantea sin que provoque mayores desaciertos de los que presente su vigencia. $Y$ restringida en la medida de que se pueda cumplir un principio constitucional básico de estabilidad del ordenamiento, en este caso constitucional. $Y$ hechas estas consideraciones es el momento de abordar la cuestión de una eventual reforma de los artículos que regulan estos derechos.

\section{LA FASE CONSTITUYENTE}

En la fase constituyente es interesante contrastar las diferentes redacciones que tienen lugar en los artículos 7 y 37 de la Constitución Española, de cara a determinar cuáles eran los valores que llevaban a las diferentes posiciones políticas a pretender la imposición de uno u otro modelo de sindicación.

Las discusiones parlamentarias que precedieron a la aprobación del texto de los arts. 7, 28 y 37, ponen de manifiesto la polaridad de las fuerzas políticas en los temas de significación sindical. En tal sentido los debates de socialistas y comunistas expresaban las filosofías contrarias al centro y la derecha políticas. Los primeros pretendían expresar en el texto la tensión de la lucha de clases, mientras que los partidos políticos UCD y AP mantenían una visión de la sociedad basada en la integración de intereses de empresarios y trabajadores. Salvo los socialistas de Cataluña que como se sabe constituían grupo parlamentario diferenciado del grupo socialista, no hay especial incidencia de los partidos políticos autonómicos en estos temas, preocupados a la sazón en defender sus posiciones nacionalistas.

En los debates constitucionales que se produjeron con motivo de la discusión parlamentaria del Proyecto (5-5-78), se puede destacar la intervención de Carrillo que capta ya desde el primer momento la eventual arbitrariedad sobre "el nombramiento de los servicios mínimos" en los casos de huelgas declaradas en actividades relacionadas con la prestación de servicios esenciales de la comunidad. El tiempo se encargaría de darle la razón en la medida en que la piedra de toque del desarrollo del derecho 
de huelga ha presentado la inmensa mayoría de los problemas en lo que se refiere a las resoluciones de la autoridad gubernativa en el nombramiento de estos servicios mínimos.

En lo que se refiere al art. 7, la mayoría de los debates se centraron en cuanto a cuáles eran las organizaciones que gozaban de reconocimiento constitucional expreso, introduciéndose dos enmiendas in voce, la primera por Peces Barba, referida a invertir el orden de los sujetos y a la orientación a la «defensa y promoción de intereses». La segunda por Herrero de Miñón integrando también a los Colegios Profesionales entre las organizaciones de reconocimiento constitucional.

El Grupo Parlamentario de Alianza Popular pretendía mantener la ponencia como estaba, pero tras las reservas de socialistas y comunistas acerca de la constitucionalización de los Colegios Profesionales, y de la apostilla final de los «intereses que les son propios", se aprobó por unanimidad el texto que ya no tendría más modificaciones.

El art. 28 de la CE es probablemente el que mayor densidad ideológica. Inicialmente redactado el pf. 2 como que «la ley no podrá atentar al mantenimiento de los servicios esenciales", queda al final como "la ley establecerá las garantías precisas para asegurar el mantenimiento".

Es uno de los más dialécticos en la tramitación parlamentaria. El derecho de huelga, en principio en el art. 26 del Proyecto, mostraba la ideología política de los grupos.

AP pretendía eliminar las huelgas políticas y de solidaridad. Su enmienda establecía tres limitaciones al derecho de huelga: La seguridad nacional, intereses generales o servicios esenciales de la comunidad. Los socialistas estimaron que era el artículo básico para los trabajadores. Defendieron abiertamente la huelga política. "Si ignorásemos las huelgas políticas, que han abierto cauce a la conquista de derecho para la clase trabajadora, probablemente estaríamos ignorando gran parte de la historia política y sindical de Europa de las últimas décadas." (Saavedra Acevedo, C.E. Trabajos Parlamentarios, 4064). Alude a los sucesos de mayo del 68, y sobre todo a la imposibilidad de acotar el campo de lo político. Se abstiene AP y en la explicación de voto, Fraga dice que no cree en la lucha de clases ni le parece correcta la imposición de una clase sobre otra.

UCD explica su voto afirmativo entendiendo que no vota la huelga política sino a lo peor las huelgas mixtas y que ante la huelga derecho y la huelga libertad, la UCD está votando la huelga derecho.

Los comunistas, a través de Solé Tura explican su voto afirmativo 
porque su lectura del art. 26 es amplia, y el concepto "sus intereses" es inherente al interés social en su conjunto.

Peces Barba pregunta si sería ilegal una huelga en defensa de la democracia y contra el terrorismo.

El art. 37 considerado como la constitucionalización del sindicalismo y el reconocimiento de la lucha de clases, tiene un mayor fragor parlamentario.

Por parte de AP se propone reconocer sólo la medida de conflicto colectivo a los empresarios, en un intento de compensar el derecho de huelga. Proponían: «se reconoce el derecho empresarial a la defensa de su actividad..". Los socialistas piden votación separada de los dos párrafos para abstenerse en el segundo. Igual los comunistas.

El derecho de sindicación estaba planteado como síntesis de dos modelos, el de las secciones sindicales, aspiración de UGT porque era el modelo de trabajo de progresiva implantación en las empresas, y el modelo de comités de CC.OO. que pretendía la implantación representativa de asamblea.

Lo que se constitucionaliza es el primer modelo de sindicación que otorga a los sindicatos el papel de contribuir a la defensa y promoción de intereses, siendo los comités de empresa órganos de creación legal.

En ambos casos, el modelo otorga el protagonismo a dos centrales, y obvia la acción directa de los trabajadores, limitados a la acción individual.

\section{EL DESARROLLO LEGISLATIVO Y LA JURISPRUDENCIA DEL TRIBUNAL CONSTITUCIONAL}

Ley Orgánica 11/85, de 2 de agosto de libertad sindical.

Ley $8 / 80$ de 10 de marzo del Estatuto de los Trabajadores.

El desarrollo legislativo incide en la filosofía del Sindicato más representativo, (arts. 6 y 7 de la ley 11/85), y estructura la participación sindical en la empresa a través de una doble presencia: las secciones sindicales y los Comités de empresa intentando combinar ambos modelos. 
Fija las conductas antisindicales como materia de tutela efectiva en cumplimiento del art. 53 de la CE, pero exporta el procedimiento a la ley $62 / 78$ de PJDF, que no especifica el proceso laboral, de modo que se sigue teóricamente a través de la vía civil pero en sede jurisdiccional social. La resultante es una incertidumbre jurisprudencial en las instancias que el TC interpreta en líneas generales a favor del ejercicio del derecho fundamental lesionado. (ST. del TC 51/88).

La nueva regulación laboral del proceso por delegación legislativa, el RDLeg. 521/90, de 27 de abril, ha intentado obviar estas dificultades creando a su vez otras insalvables.

Como novedades atractivas, la ley establece una inversión de la carga de la prueba en los supuestos de discriminación sexual, discriminación en general, y violación de derechos sindicales. Pero diferencia los procesos por tutela puros de todos aquellos procesos de por sí especiales en los que se da una supuesta discriminación. A los primeros les establece un proceso rápido, conforme el art. 53, con citación al Ministerio Fiscal, y con posibilidad de suspensión del acto discriminatorio y adopción de medidas judiciales preventivas. Pero el despido, que es eventualmente la actuación empresarial donde culmina una discriminación sindical, se tramitará «inexcusablemente por su modalidad procesal correspondiente». En tal caso los jueces y Tribunales Superiores han venido entendiendo que no es preciso citar al Ministerio Fiscal en los procesos por despido discriminatorio. EI TC todavia no ha tenido ocasión de pronunciarse.

Con todo, e independientemente de este problema central, hay una cuestión global que afecta por igual a la efectividad de todos los derechos sindicales y es la escasa efectividad de los pronunciamientos judiciales. El fallo del juez que condena al empresario a que cese en su discriminación, así entendido como una mera declaración o advertencia, no tiene posibilidad de ejecución, de modo que la persistencia de su actitud obliga a una nueva demanda, que en el orden jurisdiccional laboral no tiene más fin que la indemnización por daños y perjuicios, si es que se prueba un perjuicio material y moral no presumido ni siquiera iuris tantum.

\section{El desarrollo jurisprudencial del TC}

EI TC desarrolla el modelo de sindicación establecido en los arts. 28 y 37 de la CE. La ST. 124/88 desestima el amparo de trabajadores de Pueblo que pretendían impugnar el convenio colectivo en el ejercicio de una acción procesal directa y colectiva. 
Aludian los recurrentes a que un reglamento administrativo lo pudiera impugnar cualquier ciudadano y un trabajador no pudiera impugnar un convenio que le era de aplicación.

Por lo demás la interpretación del TC a los arts. 7, 28 y 37, ha sido de la mayor amplitud y expansión del derecho fundamental.

La ST. 51/88 estima de cobertura legal, no de contenido esencial, el derecho a presentar candidaturas, y que pese a su reconocimiento legal es amparable en lo constitucional. Resuelve sobre recurso de amparo que promueve la central CC.OO. contra El Corte Inglés porque no se le permite subsanar los defectos de una candidatura presentada por la central a las elecciones sindicales. EI TC desestima, con el voto particular de Rodríguez Piñero que consideró de aplicación una interpretación extensiva del derecho fundamental, pero esta sentencia tiene la virtualidad de integrar elementos de configuración legal dentro del contenido esencial del derecho sindical.

Distinguiendo entre los diferentes derechos de configuración sindical, los criterios del TC son:

1. En cuanto al derecho de huelga:

a) Se debe regular por ley orgánica, (ST. 33/81).

b) Es competencia estatal que no puede ser objeto de regulación por las CC.AA. (33/81).

c) Los servicios esenciales son, según la ST. 26/81, aquellas actividades de las que derivan prestaciones vitales o necesarias para la sociedad. Y éstos son los derechos fundamentales, las libertades públicas y los bienes constitucionalmente protegidos. Su nombramiento incumbe a la Administración del Estado que tenga atribuidas las competencias de la actividad donde se ejerza el derecho de huelga. (Es el sentido de la ST. 33/81 que anula el decreto del Gobierno central acerca de servicios mínimos al metropolitano de Barcelona).

2. En cuanto a los conflictos colectivos:

a) Son competencia estatal. (Se establece este criterio ya en la ST. 18/82, que conoce el conflicto de competencias acerca de 
las funciones en el Centro de mediación, arbitraje y conciliación del gobierno Vasco). El reparto de competencias en este caso abarca este centro, en el Registro y demás cuestiones de funcionamiento interno, que se estiman competencia de las CC.AA., manteniendo la competencia estatal para los conflictos colectivos de trabajo.

b) La legitimación activa de los sindicatos para interponer los conflictos colectivos arranca del mismo art. 37 y tiene protección constitucional porque se enmarca en el art. 28 susceptible de amparo. (ST. 37/83).

3. En cuanto a la negociación colectiva:

a) Es competencia estatal. La competencia de las CC.AA. va sólo referida a la ejecución de acuerdos. (ST. 35/82).

b) La autonomía de las partes tiene como límite la ley. (ST. 136/87).

El Tribunal Constitucional ha entendido por otra parte que el criterio interpretativo a utilizar era el de dar la mayor amplitud posible a la realización del derecho fundamental. De ahí que su idea del contenido esencial fuera referida no estrictamente al art. 28 sino a la combinación conjunta de la normativa constitucional referida al conjunto de los derechos sindicales.

\section{Respecto del contenido esencial:}

No lo forma el derecho a participar en asuntos públicos, o a formar parte de las instituciones públicas (ST. 53/82), porque no está en contradicción con el concepto de sindicato más representativo. En cuanto al derecho de sindicación lo forma el derecho a constituir sindicatos, a afiliarse a los existentes, a no afiliarse, y a desempeñar las funciones del art. 7 de la CE. (ST. 70/82).

$Y$ para el ejercicio de la actividad sindical es imprescindible que se reconozca la capacidad procesal, legitimación activa y pasiva, a las organizaciones sindicales. EI TC ha entendido así el contenido esencial del derecho al ejercicio de la libertad sindical en esta sentencia 72/82. La ST. de instancia había desestimado la demanda de la central sindical UGT por entender que sólo la tenía el Comité de empresa. La base legal era el art. 18 
del RD $17 / 77$ de 4 de marzo sobre relaciones de trabajo y 65.1 del ET. EI TC aplica además el 87 del ET.

Forma parte del contenido esencial de la libertad sindical, el derecho a la negociación colectiva sin el cual se desnaturaliza la libertad sindical. Otra cosa es la eficacia erga omnes o limitada de esta negociación.

La 37/83 acaba de implantar el criterio amplio de interpretación de la legitimación ad causam de los sindicatos. En el fj 2 relaciona tres normas: "La función de los Sindicatos no consiste únicamente en representar a sus miembros a través de esquemas de apoderamiento y de la representación del derecho privado, sino que, cuando la Constitución y la ley les invisten con una función social, con la función de defender los intereses de los trabajadores, les legitiman para ejercer aquellos derechos que, aún perteneciendo en puridad a cada uno de los trabajadores uti singuli, sean de necesario ejercicio colectivo, que al reconocer en su art. 28.1 la libertad sindical, no está admitiendo sólo el derecho de los trabajadores a sindicarse libremente o el derecho a fundar sindicatos y afiliarse al de su elección sino también, por la necesaria remisión al art. 7 del que es interdependiente el derecho de los sindicatos a actuar libremente (...) permitiendo así que la propia actividad del sindicato (...) se integre en el art. 28 de la Constitución. La libertad sindical implica la libertad para el ejercicio de la actividad sindical (...). De esta forma, el art. $\mathbf{3 7 . 2}$ de la Constitución se conjuga con el art. 37.1 y con el 28.2 para definir el ámbito del ejercicio de la libertad sindical».

Con ello se produce una curiosa exportación del 37 al 28 manera que acaba teniendo cobertura de DF el derecho a la negociación colectiva y conflicto colectivo en sede del 28 (ST. 4/83) el derecho de negociación colectiva sólo tiene amparo cuando afecta al derecho de libre sindicación. En igual sentido la 73/84, que estima el recurso de amparo de CC.OO. a participar en la revisión del convenio aunque no firmara el texto del convenio a revisar).

No forma parte del contenido esencial en general el derecho de negociación colectiva por faltar el nexo causal entre ambos conceptos (ST. $57 / 82$, sobre el derecho a la negociación colectiva de los funcionarios).

Caben diferentes contenidos esenciales según la implantación del sindicato, porque el contenido esencial se mejora por ley.

Por último es importante el desarrollo jurisprudencial que efectúa el TC respecto del modelo de sindicación. Comoquiera que la constitucionalización se predica solamente de los Sindicatos y no de la representación de los trabajadores en general, la jurisprudencia del TC ha entendido que la 
protección constitucional solamente abarca a los sindicatos en detrimento de los Comités de empresa. (ST. 118/83 fj 4: "la existencia de un sistema sindical dual en el que la acción sindical en cuanto tal puede ser ejercida por Comités y por Sindicatos, ello no significa que exista una indefinición constitucional ni una identidad entre todos los sujetos susceptibles del ejercicio de las funciones sindicales. Por el contrario, el art. 7 de la Norma Fundamental constitucionaliza el Sindicato no haciendo lo mismo con el Comité de empresa, que es creación de la Ley").

La consecuencia de todo ello es que los Comités de empresa no tienen amparo sindical. (ST. 45/84, en la que se deniega a una asociación el amparo constitucional en una negociación de convenio. Igualmente la ST. 98/85).

La vía indirecta habría sido el art. 24 de la Constitución en cuanto exigencia de una tutela judicial efectiva por negación del derecho a la jurisdicción, o el 14 por discriminación, pero el TC desestimó ambas vías.

\author{
III. CONCLUSIONES DE LA PONENCIA \\ RESPECTO A LA IDEA CENTRAL DE REFORMA DE LA CE
}

PRIMERA

Se suprimiría el párrafo segundo del art. 28 en lo que se refiere a "la ley que regule el ejercicio de este derecho", cambiando esta frase por las palabras: «Se establecerán».

El párrafo segundo del artículo 28 que reconoce el derecho de huelga, establece una limitación importante a la libertad sindical. Se trata de la exigencia de desarrollo legal. Los sindicatos han defendido la autorregulación en el ejercicio del derecho fundamental del derecho de huelga, pero las asociaciones empresariales se aferran al contenido del art. 28 para estimar que incluso se ha incumplido el mandato constitucional.

A esto hay que hacer las siguientes consideraciones:

a) No todos los derechos fundamentales han de tener a fortiori un desarrollo legal. El derecho a la igualdad no lo ha tenido y es el artículo que virtualmente ha tenido una mayor casuística en el desarrollo jurisprudencial de los derechos fundamentales por parte del Tribunal Constitucional. 
b) El desarrollo legal recorta necesariamente el derecho de huelga, y el derecho sindical porque limita las funciones de los sindicatos, dejando en manos de la Administración armas de lucha sindicales que convierten a la Administración muchas veces en juez y parte.

SEGUNDA

La interpretación del TC ha sido muy amplia a favor de los sindicatos. Ha habido una gran influencia de los convenios de la OIT en las sentencias del TC, cuyo reflejo europeo en las resoluciones judiciales se deja notar también en otros derechos fundamentales, como en la libertad de expresión, el derecho a un proceso sin dilaciones indebidas, y otros. Esto condiciona en gran parte la adecuación en general de la norma constitucional y el hecho de que no se piense en fórmulas alternativas, por entender que con abstracción de la lectura propiamente gramatical, el TC ha asimilado el hecho sindical y ha apoyado con sus resoluciones un concepto de sindicación acorde con la realidad socio-económica.

TERCERA

El desarrollo legislativo ha sido sin embargo muy restrictivo y tardío. Además de ello ha ido en regresión, al menos en la nueva ley de procedimiento laboral en lo que se refiere a la tutela de derechos fundamentales de configuración sindical.

CUARTA

Respecto al modelo dual de representación sindical que deja fuera de protección constitucional, aunque no legal, la actividad de los Comités de empresa no sindicados, la pregunta es si cabe concluir en una reforma de la Constitución que integre a los Comités de empresa en la Constitución. $Y$ para responder a ello no hay una posición unívoca, sino dialéctica que integre los siguientes argumentos:

La mayor importancia del sindicato evita el amarillismo en las empresas porque exporta los problemas a soluciones más distantes e impide el revanchismo. 
Pero a ese argumento se opone la burocratización y distanciamiento de los sindicatos en relación con los Comités de empresa cuya mayor apariencia democrática la otorga el hecho de responder a una representación más directa.

Por otra parte, la mayoría de los Comités de empresa se articulan a través de las organizaciones sindicales, siendo opciones muy minoritarias las de ausencia de sindicación.

QUINTA

Las vías de opción a reforma son:

Concentrar en un solo artículo todos los derechos de sindicación: reconocimiento de los sindicatos, huelga, negociación, conflicto. De modo que un superartículo 28 absorba a los demás.

Las declaraciones jurisprudenciales del TC han ido precisamente en el sentido de correlacionar toda esta normativa.

A este planteamiento se oponen sin embargo razonamientos no solamente técnicos, sino de política constitucional, pues a nadie se le oculta que esta regulación trae consigo una importancia social de los sindicatos que por definición en estos momentos no fuera compartida por más de la décima parte del Parlamento, 0 aún ni eso.

SEXTA

Se iria a un desarrollo de la normativa postconstitucional en materia sindical mucho más garantista porque pese a la profusión normativa, los derechos sindicales de los trabajadores y de los sindicatos, están muy lejos de ser protegidos de forma fehaciente. Pero esta es una conclusión que no se puede efectuar con abstracción de la ejecutoriedad del resto de los derechos fundamentales, pues igualmente formalista acaba siendo el amparo de otros derechos fundamentales, por citar un caso extremo el de denuncia de las dilaciones indebidas o el de libertad de expresión cuya situación en el tiempo hacen inefectivos los pronunciamientos que pretendan retrotraer los efectos. 
Aun cuando por la naturaleza propia de los derechos sindicales, los efectos mediatos son más nulos que en los asuntos individuales o de naturaleza no social. El caso cumbre es la $73 / 84$, que tras reconocer la legitimación de CC.OO. para revisar un acuerdo de enero del 83 en junio del 84 , el fj 5 determina "limitar el pronunciamiento de este tribunal al reconocimiento del derecho, de conformidad con su contenido constitucionalmente garantizado, sin otorgar a esta declaración eficacia retroactiva y manteniendo la validez juridica de las situaciones producidas". Situaciones como ésta hacen reflexionar acerca de cuál puede ser la satisfacción de un derecho obtenido en esas circunstancias y su relación con el esfuerzo que realizan las partes para conseguirlo.

RESEÑA DE SENTENCIAS DEL TRIBUNAL CONSTITUCIONAL

$\begin{array}{rrr}3 / 81 & 49 / 83 & 67 / 85 \\ 22 / 81 & 58 / 83 & 71 / 85 \\ 25 / 81 & 73 / 83 & 98 / 85 \\ 26 / 81 & 118 / 83 & 141 / 85 \\ 33 / 81 & 18 / 84 & 39 / 86 \\ 18 / 82 & 23 / 84 & 136 / 87 \\ 35 / 82 & 26 / 84 & 160 / 87 \\ 51 / 82 & 31 / 84 & 9 / 88 \\ 53 / 82 & 45 / 84 & 51 / 88 \\ 57 / 82 & 51 / 84 & 57 / 88 \\ 69 / 82 & 63 / 84 & 124 / 88 \\ 72 / 82 & 73 / 84 & 235 / 88 \\ 4 / 83 & 20 / 85 & 57 / 89 \\ 11 / 83 & 26 / 85 & 61 / 89 \\ 37 / 83 & 58 / 85 & 89 / 89\end{array}$

